\title{
Práticas e Políticas Educacionais na América Latina
}

\author{
Políticas y prácticas educativas en Latinoamérica
}

\author{
Educational Policies and Practices in Latin America
}

\author{
Alessandra Fontes Carvalho da Rocha ${ }^{1}$ \\ Washington Kuklinski Pereira²
}

\begin{abstract}
Resumo
As políticas públicas de educação ao redor do mundo estão passando por um processo de padronização internacional - destacamos, por exemplo, o sistema PISA (Programme for International Studant Assiment). Na contramão dessas ações de mecanização do processo de ensino-aprendizagem, professores procuram promover práticas educativas que priorizam a formação crítica, lúcida e reflexiva dos estudantes. Ao submetermos uma proposta de simpósio ao I Seminário Latino-Americano de Estudos em cultura, o nosso interesse foi, além de problematizar questões referentes à educação, construir um espaço de discussão e reflexão sobre tal temática vislumbrando possibilidades de trabalhos e ações que tivessem como eixo norteador a quebra do paradigma normativo das atuais políticas de padronização do processo ensino-aprendizagem. Com esse intuito, surge o Simpósio Temático - 08, intitulado Práticas e Políticas Educacionais na América Latina, que teve como objetivo principal reunir pesquisadores, principalmente professores-pesquisadores, e licenciandos em formação que discutissem as políticas de educação atuais e trouxessem relatos de experiência sobre suas práticas educacionais no Ensino Fundamental, Ensino Médio e Ensino Superior. É a partir desses apontamentos e interesses que apresentamos neste artigo as reflexões empreendidas durante os três dias de encontro no nosso simpósio.
\end{abstract}

Palavras-Chave: Educação; Políticas Educacionais; Práticas Educacionais; América Latina; Processo ensinoaprendizagem.

\section{Resumen}

Las políticas de educación pública en todo el mundo están pasando por un proceso de normalización internacional - siguiendo el ejemplo del PISA (Programme for International Studant Assiment). Frente a estas acciones de mecanización del proceso de enseñanza-aprendizaje, los docentes intentan promover prácticas educativas que prioricen la formación crítica, lúcida y reflexiva de los alumnos. La propuesta de un simposio al Primer Seminario Latinoamericano de Estudios Culturales nos interesó, además de la problemática de la

1 Doutora em Estudos de Literatura; professora de Didática e Prática de Ensino Português - Literaturas; Universidade Federal do Rio de Janeiro; Rio de Janeiro; Rio de Janeiro; Brasil; contato: profa.alessandra.fontes@gmail.com; Trabalho apresentado no I Seminário Latino-Americano de Estudos em Cultura - SEMLACult, Foz do Iguaçu/PR, Brasil, 2017.

${ }^{2}$ Doutor em História pela Pontifícia Universidade Católica de São Paulo; Professor da Fundação de Estudos do Mar;Professor da Secretaria Municipal de Educação do Rio de Janeiro, atuando nas escolas Frei Gaspar e Comunidade Vargem Grande; Contato: prof.washington.kuklinski@gmail.com; Trabalho apresentado no I Seminário Latino-Americano de Estudos em Cultura - SEMLACult, Foz do Iguaçu/PR, Brasil, 2017. 
educación, para construir un espacio de discusión y reflexión sobre este tema, buscando posibilidades de obras y acciones que tenían como eje romper la normativa y paradigma de las actuales políticas públicas de estandarización del proceso de enseñanza-aprendizaje. Se creó el Simposio Temático 08, titulado Prácticas y Políticas Educativas en América Latina, cuyo objetivo principal fue reunir a investigadores, principalmente docentes-investigadores y graduados en formación, que discutieron las actuales políticas de educación pública e informaron sobre la experiencia educativa prácticas en la escuela primaria, la escuela secundaria y la universidad. Es a partir de estas notas e intereses que presentamos en este artículo el resultado de nuestro trabajo durante los tres días de reunión en nuestro simposio.

Palabras-Claves: Educación; Políticas Educativas; Prácticas Educativas; Latinoamérica; Proceso de enseñanza-aprendizaje.

\begin{abstract}
The public education policies around the world are undergoing an international standardization process following the example of PISA (Program for International Studant Assessment). Against to these actions of mechanization of the teaching-learning process, teachers try to promote educational practices that prioritize the students' critical, lucid and reflective formation. The submition of a proposal for a symposium to the First Latin American Seminar on Cultural Studies, our interest was, the addition to problematizing issues related to education, to construct a space for discussion and reflection on this theme, looking at possibilities of works and actions that had as their axis break the normative and paradigm of the current public policies of standardization of the teaching-learning process. The Thematic Symposium - 08, entitled Educational Practices and Policies in Latin America, was created, whose main objective was to bring together researchers, mainly teachers-researchers, and graduates in formation who discussed current public education policies and brought reports the experience about their educational practices in the elementary school, high school and college. It is from these notes and interests that we present in this article the result of our work during the three days of meeting in our symposium.
\end{abstract}

Keywords: Education; Educational Policies; Educational Practices; Latin America; Teaching-learning process.

\title{
1. Introdução
}

Seria uma atitude ingênua esperar que as classes dominantes desenvolvessem uma forma de educação que proporcionasse às classes dominadas perceber as injustiças sociais de maneira crítica. (Paulo Freire)

Assim como é apontado na epígrafe que abre as discussões deste artigo, a proposta do simpósio temático que se quer aqui apresentar ousou e se atreveu falar sobre educação sem nenhuma ingenuidade. Afinal, falar de políticas e práticas educacionais sendo ingênuo é inviável quando se pensa em querer quebrar paradigmas. É com as palavras de Paulo Freire que iniciamos a apresentação de nossa caminhada, em junho de 2017, durante o I Seminário Latino-Americano de Estudos em cultura.

Ainda que estejamos falando no e do século XXI, é imprescindível retomarmos algumas questões que historicamente nos parecem tão distantes. Dominantes e dominados, dentro de um quadro educacional que se apresenta como de direito a todos, pois segundo o 
artigo 205 da Constituição Brasileira de 1988: "A educação, direito de todos e dever do Estado $^{3}$ e da família, será promovida e incentivada com a colaboração da sociedade, visando ao pleno desenvolvimento da pessoa, seu preparo para o exercício da cidadania e sua qualificação para o trabalho.”, continuam a refletir realidades bem diferentes. Em um contexto que se apresenta tão democrático como o exposto a partir da citação de nossa principal lei, colocamos no centro de nossas discussões os seguintes questionamentos: Que educação se quer e interessa para esse todo? Quem de fato faz parte desse todo? Qual o objetivo de uma educação nacional para esse todo?

Mesmo sabendo já ser senso comum ouvir que, na prática, a teoria é muito diferente, trazemos essa afirmação a fim de salientar o quanto é diferente de fato, mas também para mostrar o quanto a teoria pode levar a práticas que reproduzem cada vez mais as diferenças sociais e econômicas. E esse é exatamente um dos nossos interesses ao propormos um simpósio temático com eixo central na educação e em suas políticas e práticas.

As políticas públicas de educação ao redor do mundo estão passando por um processo de padronização internacional. O sistema PISA (Programme for International Studant Assiment), que conta atualmente com a participação de 32 países, promove testes internacionais com o objetivo de estabelecer níveis de aprendizado. Para tanto, são criados sistemas genéricos de avaliação que desprezam as particularidades de cada região analisada. Além disso, há a proposta de mecanização do conhecimento, sendo estabelecidos apenas parâmetros para mensurar pseudo competências sobre o entendimento de Ciências, Matemática e a capacidade de leitura dos estudantes.

Atualmente, Brasil, Chile, Colômbia, Costa Rica, México, Peru, República Dominicana e Uruguai são países que se tornaram signatários do sistema PISA. Sendo assim, as políticas públicas destes países passaram a estabelecer metas que direcionam o processo ensino-aprendizagem a uma formação genérica que atenda aos parâmetros internacionais e desprezam a formação crítica do indivíduo. Nesse sentido, se retomarmos os questionamentos acerca da educação que se quer para o todo que tem direito à educação, percebemos que o objetivo dessa padronização é a formação de um grupo homogênio que seja incapaz de ser questionador de sua própria realidade.

$\mathrm{Na}$ contramão desse processo de mecanização do processo de ensino-aprendizagem, professores procuram promover práticas educativas que priorizam a formação crítica dos

\footnotetext{
${ }^{3}$ Atualmente, o Brasil passa por um processo de discussão acerca da obrigatoriedade de oferta da educação pública por suas esferas administrativas.
} 
estudantes. Além disso, há propostas de políticas públicas para a educação que seguem perspectivas diferentes do sistema PISA. Nesse sentido, o objetivo do Simpósio Temático 08 Práticas e Políticas Educacionais na América Latina é reunir pesquisadores que discutam as políticas públicas de educação e relatos de experiência de professores e estudantes dos cursos de Licenciaturas sobre suas práticas educacionais no Ensino Fundamental, Ensino Médio e Ensino Superior.

\section{Da teoria à prática: um caminho com muitos percalços}

Como já mencionado anteriormente, na teoria, todos que formam uma sociedade têm direito à educação. Sendo assim, nos resta pensar se de fato os que formam o todo, da teoria à prática, são atendidos e, independente da oferta, que tipo de educação recebem. Assim, chegaremos ao cerne de nossa discussão: o que é de interesse - importante pensar também: interesse de quem? - que as pessoas recebam durante a formação nas instituições formais de ensino?

Segundo Novaski,

Dizem que educar, etimologicamente, significa "levar de um lugar para outro". Concordo. Aliás, creio ser às vezes importante recuperar a etimologia dos conceitos, quando isso significa uma recuperação da densidade da vivência que se tem, vivência sempre expressa com palavras. "Levar de um lugar para outro", está aí uma vivência cuja densidade pode significar um aumento incalculável de experiências, configurando aquilo que fundamenta um processo de ensino-aprendizagem realmente humano. (NOVASKI, 1994, p. 11)

É refletindo sobre a concepção de educação e de processo ensino-aprendizagem descrita por Novaski que iremos empreender nossas reflexões a partir da seguinte compreensão: são necessários planos de educação e um processo ensino-aprendizagem realmente humanos para o humano, incluindo vivências e experiências na vida dos estudantes, que os levem de um lugar para outro. 
É o movimento de "levar de um lugar para outro", como significado etimológico de educar $^{4}$, que servirá como ponto de partida para a abordagem das políticas educacionais em nível de América Latina e as práticas docentes de que temos e teremos notícias durante as apresentações dos diferentes trabalhos de professores e estudantes ${ }^{5}$, agentes sociais que se importam com o ensino e que fazem dele objeto de pesquisa.

De onde e para onde nossos estudantes estão sendo levados, estando eles na educação básica ou no ensino superior? Era a resposta a esse questionamento que procurávamos e continuamos a buscar quando propusemos um simpósio com o tema políticas e práticas educacionais. O que está no papel como proposta para o ensino e para a educação e o que tem chegado às salas de aula? Para chegar a alguma conclusão, entendemos ser urgente escutar nossos pares, a fim de trocarmos experiências e colocarmos em pauta tudo que rege o sistema educacional ainda nos dias de hoje.

Vivemos em uma realidade educacional onde fatores exógenos são os norteadores do ato de educar. Isso é decorrente da dependência de capital externo por parte dos países latinoamericanos, o que transformou o processo ensino-aprendizagem em uma garantia para empréstimos feitos por fundos monetários internacionais. O desenvolvimento da educação desde a década de 1990 se tornara uma espécie de "garantia" para investimentos econômicos por parte da Europa e dos Estados Unidos em países considerados de economia subalterna. Logo, surgiram formas de pensar o processo de ensino-aprendizagem de forma mais objetiva, desprezando as particularidades de cada grupo escolar. Foram, então, criados índices de aprovação e o alargamento do conceito de alfabetização. Assim, para atender os índices impostos, a educação passou a fazer parte do "campo da colonialidade".

Além disso, a questão acima é apenas uma das muitas que nos fazemos ao pensar em uma educação que seja parte de uma pedagogia decolonial em suas práticas e políticas, ou seja, formas de transformar a sala de aula num lugar de resistência aos modelos de políticas de educação que visam à padronização bancária do processo ensino-aprendizagem. Para Boaventura de Souza Santos, esse processo de decolonialidade seria "um conjunto de práticas e discursos que desconstroem a narrativa colonial como foi escrita pelo colonizador, e tenta substituí-la por narrativas escritas do ponto de vista do colonizado" (SANTOS, 2002, p. 13). Mas, para isso, é necessário que o sujeito seja livre para ser e pensar a partir de suas

\footnotetext{
${ }^{4}$ Segundo Augusto João Crema Novaski em "Sala de aula: uma aprendizagem do humano".

${ }^{5}$ É importante destacar que, durante o Simpósio Temático 08 - Práticas e Políticas Educacionais na América Latina, tivemos a apresentação de trabalhos de licenciandos e estudantes de cursos de pós-graduação.
} 
experiências, suas crenças, suas opiniões, lugar onde está inserido, sua língua e suas linguagens, construindo um movimento oposto ao da monocultura do pensamento.

O questionamento acima também é o primeiro passo para analisarmos ações pedagógicas que só reafirmam o neocolonialismo da educação, que, ao contrário de levar para algum lugar, só fixam os sujeitos em formação em um terreno de manutenção das hierarquias já estabelecidas aos "condenados da terra"6. É no início da obra "Pedagogia da Autonomia" que Paulo Freire proclama seu posicionamento ético e o que deveria ser o de educadores e educadoras.

\begin{abstract}
"Daí o tom de raiva, legítima raiva, que envolve o meu discurso quando me refiro às injustiças a que são submetidos os esfarrapados do mundo (...) Em tempo algum pude ser um observador 'acinzentadamente' imparcial, o que, porém, jamais me afastou de uma posição rigorosamente ética (...) O meu ponto de vista é o dos "condenados da Terra", o dos excluídos. (...) Este pequeno livro se encontra cortado ou permeado em sua totalidade pelo sentido da necessária eticidade que conota expressivamente a natureza da prática educativa, enquanto prática formadora. Educadores e educandos, não podemos, na verdade, escapar à rigorosidade ética. Mas, é preciso deixar claro que a ética de que falo não é a ética menor, restrita do mercado, que se curva obediente aos interesses do lucro." (FREIRE, 1997, p. 15-17)
\end{abstract}

O autor aponta a importância de uma reflexão crítica e da afirmação de um compromisso com uma ação pedagógico-política, tendo como alvo os seres humanos negados, excluídos do sistema hegemônico vigente. Ele ainda esclarece que “[...] é preciso deixar claro que a ética de que falo não é a ética menor, restrita do mercado, que se curva obediente aos interesses do lucro.”. Freire alerta para a uma ética do povo e para o povo; do humano e para o humano.

É apenas com uma educação que privilegie a formação plena do potencial humano que teremos a chance de um engajamento ativo do indivíduo atuando como peça principal para reflexão e transformação de seu mundo, frente a problemas sociais, políticos, econômicos e culturais, além do apagamento do processo de silenciamento que algumas classes sofrem em nossa sociedade.

Desse modo, as práticas docentes devem ser pautadas em uma educação como prática da liberdade, excluindo qualquer vestígio da famosa educação bancária que, segundo Freire:

\footnotetext{
${ }^{6}$ A expressão apresenta um diálogo com o pensamento de Frantz Fanon, quando Freire utiliza em algumas passagens a expressão "condenados da terra" para se referir aos oprimidos; excluídos.
} 
[...] conduz os educandos à memorização mecânica do conteúdo narrado. Mais ainda, a narração os transforma em vasilhas, em recipientes a serem enchidos pelo educador. Quanto mais vá enchendo os recipientes com seus depósitos, tanto melhor educador será. Quanto mais se deixem docilmente encher, tanto melhores educandos serão. (FREIRE, 2005, p. 66)

Além de memorizar mecanicamente, nossos estudantes são comparados a vasilhas e recipientes que devem ser preenchidos e depositados com parcelas de conteúdos que são ensinados por seus professores de forma opressora, onde o docente é visto como o dono do saber e o único com autoridade em sala de aula para falar algo e ensinar. Já o discente, nesta prática, é inibido a qualquer tipo de troca e de dialogo. Tem-se a formação da sala de aula onde, muitas vezes, um finge que ensina e o outro finge que aprende, a partir de processos bancários da educação como instrumentos de opressão.

Ainda na pedagogia tradicional, o educador é o detentor do conhecimento, sendo dele a responsabilidade de transferir tudo que sabe ao estudante, tendo, este último, como única opção a tarefa de: “[...] receberem os depósitos” [realizados pelo educador], guardá-los e arquivá-los. Margem para serem colecionadores ou fixadores das coisas que arquivam" (FREIRE, 2005, p. 66).

É a partir dessas características que podemos perceber o quanto a educação e a sala de aula reproduzem a cultura do silêncio imposta pela nossa formação colonial. Vale aqui ressaltar também a marca da docilização destacada por Freire: "Quanto mais se deixem docilmente encher, tanto melhores educandos serão." (FREIRE, 2005, p. 66). Tal perspectiva nos faz mencionar a obra "Vigiar e Punir" de Michel Foucault, na qual o autor apresenta reflexões sobre as formas de disciplinarização das pessoas em diferentes instituições sociais, como por exemplo: na escola, na igreja, na família, no hospital,..., e as consequências desse processo para a vida de cada indivíduo.

É na escola, principalmente na sala de aula, que nos interessará refletir sobre a construção desse corpo dócil, ou seja, aqueles corpos obedientes, que se deixam instruir sem contestações. Sendo a docilização mais uma característica da educação bancária, é necessário percebermos quais as práticas pedagógicas que ainda acontecem em nossas escolas e que, mesmo de forma velada, produzem estudantes "bonzinhos" que nada questionam e apenas reproduzem o que é orientado por seus professores, garantindo a ordem e o bom funcionamento de uma sociedade. 
Além da docilização dos corpos, sendo por meio de violência física ou simbólica, o que nos interessa é pensar nas formas utilizadas para domar a consciência do ser humano. Partindo da ideia de que não só o corpo, mas a mente, os pensamentos dos sujeitos também são vigiados e punidos nas salas de aula, passamos dos efeitos da palmatória aos resultados de práticas docentes que auxiliam na padronização e mecanização dos conhecimentos trabalhados nas escolas, a fim de formar sujeitos passivos e condenados à submissão, à aceitação e à alienação, ou seja, corpos úteis para a manutenção da hierarquização existente no campo social. Segundo Medina,

A escola é, em grande escala, aquilo que as forças dominantes da sociedade desejam que ela seja. No sentido oficial, digamos assim, uma de suas funções fundamentais é manter o controle social através da estabilidade e do ajustamento. [...] Isto não quer dizer que a escola seja uma instituição estática e absolutamente reprodutiva do que já existe. Ela muda e se renova constantemente à medida que as contradições sociais obrigam o rearranjo da postura ou do discurso ideológico da classe dominante. [...]. Portanto, se vivemos num sistema capitalista, dependente, altamente hierarquizado em níveis sociais, não só a escola como também o homem, o corpo, e suas manifestações culturais, serão produtos ou subprodutos das estruturas que caracterizam este sistema (MEDINA, 2000, p. 19).

Se por um lado, temos a escola que se isola de seu exterior, partindo o mundo em dois: o dentro e o fora do espaço escolar; os muros altos para a delimitação desse espaço; o local assumido por discentes e docentes; os exames e os registros avaliativos dos estudantes, que tentam colocar todos em uma mesma forma e os que não se adéquam sofrem as devidas punições, por outro lado, temos as políticas de educação passando também por um processo de padronização internacional, como por exemplo: o sistema PISA (Programme for International Studant Assiment), que garante a participação de 32 países em testes internacionais para o estabelecimento de níveis de aprendizado. Segundo Araújo,

[...] por exemplo, a fila, a carteira, o treino para a escrita, os exercícios com dificuldades crescentes, a repetição, a presença num tempo e num espaço recortados, a punição pelo menor desvio de conduta, a vigilância por parte de um mestre ou monitor, as provas, os exames, os testes de aprendizagem e de recuperação, o treinamento dentro de padrões e normas fixos. E mais, os resultados dos esforços pedagógicos sendo permanentemente avaliados por critérios também eles padronizados, leva a uma simples análise de boletins, que sirva para medir os casos que desviam, portanto, serve para marcar, excluir, normalizar (ARAÚJO, 2002, p. 79). 


\section{Considerações finais}

"Fundadores e colonizadores do Império do

Brasil tinham os olhos na Europa e os pés na

América (...)" (MATTOS, 1999, p. 116)

A reflexão feita por Ilmar de Mattos, na obra $O$ Tempo Saquarema, nos faz pensar sobra a atual perspectiva das políticas públicas de Educação do Brasil e de alguns países da América Latina. "De costas" para os próprios saberes de seu povo, forjou-se um projeto educacional que tenta "padronizar" o processo de ensino-aprendizagem, a fim de seguir um modelo educacional europeu, negando, ao máximo, as características culturais e os saberes multiétnicos formadores de uma "colcha de retalhos" chamada população latino-americana.

Ao assumir como política de educação modelos conceituais desenvolvidos em outra realidade, desprezando as características dos habitantes, a educação na América Latina tornou-se um grande campo de práticas e políticas educacionais em meio a um processo neocolonial da educação. Dessa forma, os ensinamentos de Paulo Freire, intelectual da decolonialidade da educação, foram abandonados em nome de um modelo educacional que mantém os "condenados da terra" em sua condição.

É na perspectiva de um ensino que estimule o pensamento e a reflexão dos estudantes que buscamos estabelecer debates sobre pesquisas e relatos de experiências de ações pedagógicas no campo das mais diferentes disciplinas e áreas que levem os licenciandos e licenciados a refletirem sobre a profissão docente e a importância da atuação no magistério com práticas que sirvam para combater padrões educacionais que: valorizem determinada cultura em detrimento de outra; que empreguem modelos eurocêntricos; que postulem uma única verdade; e que façam da escola uma via de mão única, onde o professor é tido como o operador final de um sistema educacional que garante os interesses de uma educação neocolonial.

\section{Referências}


ARAÚJO, Inês L. Da "pedagogização" à educação: acerca de algumas contribuições de Foucault e Habermas para a filosofia da educação. Revista Diálogo Educacional, Curitiba, v. 3, n. 7, p. 75-88, set./dez. 2002.

ARROYO, Miguel. Outros Sujeitos, Outras Pedagogias. Petrópolis, RJ: Vozes, 2012.

BRASIL. Ministério da Educação. Parâmetros Curriculares Nacionais: ensino médio. Brasília: MEC, 2000.

Secretaria de Educação Fundamental. Parâmetros Curriculares Nacionais: primeiro e segundo ciclos do ensino fundamental: Língua Portuguesa. Secretaria de Educação Fundamental. Brasília: MEC/SEF, 1998. Secretaria de Educação Fundamental.

Parâmetros Curriculares Nacionais: terceiro e quarto ciclos do ensino fundamental: Língua Portuguesa. Secretaria de Educação Fundamental. Brasília: MEC/SEF, 1998.

FANON, Frantz. Os Condenados da Terra. $2^{\text {a }}$ Ed. Rio de Janeiro: Civilização Brasileira, 1979.

FOUCAULT, Michel. Vigiar e Punir: nascimento da prisão. Trad. Lígia M. Ponde Vassalo. Petrópolis: Vozes, 1987.

FREIRE, Paulo. A educação como prática da liberdade. 23ª ed. Rio de Janeiro: Paz e Terra, 1999.

Pedagogia da autonomia: saberes necessários à prática educativa. $43^{\mathrm{a}}$ ed., São

Paulo: Paz e Terra, 2011.

. Pedagogia da esperança: um reencontro com a pedagogia do oprimido. Rio de Janeiro: Paz e Terra, 2005.

. Pedagogia da indignação: cartas pedagógicas e outros escritos. $1^{\mathrm{a}}$ ed. São Paulo:

Editora UNESP, 2000.

FREIRE, Paulo; SHOR, Ira. Medo e ousadia: o cotidiano do professor. $5^{\mathrm{a}}$ edição. Rio de Janeiro: Paz e Terra, 1986.

MATTOS, Ilmar Rohloff de. O Tempo Saquarema: a formação do Estado Imperial. Rio de Janeiro: Access-Editora, 1999.

MEDINA, João Paulo. O brasileiro e seu corpo: educação e política do corpo. Campinas: Papirus, 2000.

MORAIS, Regis de. Sala de aula: que espaço é esse? Ed. Papirus, 1994.

NETO, João Colares da Mota. Paulo Freire e o pós-colonialismo na educaçãoPopular latinoamericana. Revista Educação Online nº 14, p.25-38 , ago./dez. de 2013. 
NORTON, C. Os mecanismos da escrita criativa. Lisboa: Temas e Debates - Actividades editoriais, 2001.

NOVASKI, Augusto João Crema. Sala de aula: uma aprendizagem do humano. In.:

MORAIS, Regis de. Sala de aula: que espaço é esse? Ed. Papirus, 1994.

RINCÓN, Lenin González. Neocolonialismo pedagógico VS Educación libertadora nuestroamericana. In: Portal Aporrea. Disponível

em: https://www.aporrea.org/educacion/a186225.html

VASCONCELOS, Maria Lúcia M. C.; BRITO, Helena Pires de. Conceitos de educação em Paulo Freire. 3. ed. Petrópolis/RJ: Vozes; São Paulo: Mack Pesquisa, Fundo Mackenzie de Pesquisa, 2009. 